\title{
Synthesis and self-association of dibenzothiophene derivatives for simulation of hydrogen bonding interaction in asphaltenes
}

\author{
Ying-Hui Bian ${ }^{1} \cdot$ Shao-Tang $\mathrm{Xu}^{1} \cdot$ Le-Chun Song ${ }^{1} \cdot$ Yu-Lu Zhou ${ }^{1}$ • \\ Li-Jun Zhu ${ }^{1} \cdot$ Yu-Zhi Xiang ${ }^{1}$ - Dao-Hong Xia ${ }^{1}$
}

Received: 29 November 2014/Published online: 23 July 2015

(C) The Author(s) 2015. This article is published with open access at Springerlink.com

\begin{abstract}
The dibenzothiophene derivatives, namely 2-(dibenzothiophene-2-carbonyl)benzoic acid and 2-(dibenzothiophene-2-carbonyl)alkyl benzoate, were synthesized and characterized by nuclear magnetic resonance $\left({ }^{1} \mathrm{H}\right.$ NMR), matrix-assisted laser desorption/ionization time of flight mass spectrometry, and elemental analysis. The selfassociation behavior of these dibenzothiophene derivatives in $\mathrm{CH}_{2} \mathrm{Cl}_{2}$ and $\mathrm{CH}_{3} \mathrm{CN}$ was investigated using $\mathrm{UV}$-visible absorption spectroscopy, fourier transform infrared spectroscopy, and atomic force microscopy. It was found that the carboxylic acid exhibited a strong self-association trend in $\mathrm{CH}_{2} \mathrm{Cl}_{2}$ solution at a concentration of about $5 \times$ $10^{-7} \mathrm{M}$. Hydrogen bonding of carboxyl in the dibenzothiophene derivatives was confirmed to be the main driving force for the formation of the carboxylic acid aggregates.
\end{abstract}

Keywords Dibenzothiophene derivatives - Association . Hydrogen bonding $\cdot$ Simulation $\cdot$ Asphaltenes

\section{Introduction}

Petroleum is a complex mixture of hydrocarbons and nonhydrocarbons of various molecular weights. Asphaltene, which is the densest and highest molecular weight fraction of petroleum (Rakotondradany et al. 2006; Rogel 2000;

Dao-Hong Xia

xiadh@upc.edu.cn

1 State Key Laboratory of Heavy Oil Processing, College of Chemical Engineering, China University of Petroleum (East China), Qingdao 266580, China

Edited by Xiu-Qin Zhu
Takanohashi et al. 2003), contains polycyclic aromatic hydrocarbons (PAHs) with alkyl groups, heteroatoms (mostly S, N, and $\mathrm{O}$ ), and metalloporphyrins (predominantly containing Ni and V) (Strausz and Lown 2003; Tan et al. 2009). It has been found that these components can result in strong self-association via hydrogen-bonding, alkyl-alkyl, and $\pi-\pi$ stacking interactions between the molecules (Murgich et al. 1996; Murgich 2002; Sheu 2002). Although two types of molecular models, "island" and "archipelago", have been proposed to describe the structures of molecules present in asphaltenes (Groenzin and Mullins 2000; Zhao et al. 2001; Murgich et al. 1999; Sheremata et al. 2004), the chemical identity of asphaltene remains poorly understood.

Another approach to improving understanding of the molecular structure and liquid-phase association behavior relevant to asphaltenes is to synthesize pure compounds with known chemical structures and similar physicochemical properties to those of asphaltenes, and then to examine their behavior in solution (Groenzin and Mullins 2000; Zhao et al. 2001; Tan et al. 2009; Akbarzadeh et al. 2005). Recently, a series of compounds which contain polyaromatic $\pi$-stacking and heterocyclic hydrogen bonding sites linked by aliphatic tethers have been synthesized for study of the self-association behavior of asphaltenes (Tan et al. 2009; Sheremata et al. 2004; Akbarzadeh et al. 2005). Nordgård and coworkers have investigated the surface-pressure area isotherms and gained more knowledge of their arrangement at an aqueous surface on the basis of a perylene bisimide (PBI) core with acidic groups as asphaltene model compounds (Nordgård and Sjöblom 2008; Nordgård et al. 2010). Gray and coworkers have presented a new supramolecular assembly model that combines cooperative binding by acid-base interactions, hydrogen bonding, $\pi-\pi$ stacking, metal coordination, 
hydrophobic pockets, porous networks, and host-guest complexes in the aggregation of asphaltene (Gray et al. 2011).

Recently, the topics concerning H-bonds in the selfassembly of carboxylic acids have attracted more attention (Grabowski 2008). Compounds containing-COOH groups can provide two hydrogen bonds, which are particularly promising and reliable in creating and maintaining surface order. The self-assembly aggregates formed in benzoic acid solutions depends on the number and relative placement of carboxylic acid groups (Lackinge and Heckl 2009; Clair et al. 2004; Fuhr et al. 2013; Heininger et al. 2009; Ye et al. 2007). The self-assembly of the derivatives of dibenzothiophene with carboxyl groups affects the physicochemical properties of asphaltenes.

In the present work, the design and synthesis of dibenzothiophene derivatives were studied. The aggregation behavior of carboxylic acids and carboxylic esters in different solvents was comparatively investigated. The results revealed that the formation of aggregates in these carboxylic acid solutions was mainly driven by hydrogen bonding. The dibenzothiophene derivatives could be used to simulate the hydrogen bonding interaction in asphaltenes in solutions.

\section{Experimental}

\subsection{Materials and instruments}

\subsubsection{Materials}

All the chemicals and solvents used in this work are of A.R. grade unless otherwise indicated. 1,2-dichloroethane was purified with standard distillation procedures prior to use. All reactions were performed in dry glassware under a nitrogen atmosphere. The progress of the reactions was monitored by thin layer chromatography ( $\mathrm{SiO}_{2}$, TLC). Column chromatography was carried out on silica gel (Haiyang, Kieselgel 60, 200-300 mesh) with the indicated eluents.

\subsubsection{Instruments}

Melting points were determined on a Beijing Fukai X-5A apparatus (China). The ${ }^{1} \mathrm{H}$ NMR (600 MHz) spectra were measured in $\mathrm{CDCl}_{3}$ using a Bruker AVANCE III 600 Spectrometer (Germany) with tetramethylsilane (TMS) as an internal standard. MALDI-TOF mass spectra were taken on a Bruker BIFLEX III (Germany). Elemental analysis was performed on an elemental analyzer, Vario EL III (Elementar, Germany). The FT-IR spectra were recorded with a Nicolet 6700 Fourier transform infrared (FT-IR, Thermo Scientific) spectrometer using potassium bromide pellets. Atomic force microscopy (AFM) images of the aggregates were obtained with a commercial Bruker Nanoscope IVa MultiMode atomic force microscope (Germany). The UV-visible absorption (UV-Vis) spectra were measured on Hitachi U-3900H spectrophotometer (Japan) at room temperature.

\subsection{Experimental methods}

\subsubsection{Synthesis of dibenzothiophene derivatives}

The synthesis routes of 2-(dibenzothiophene-2-carbonyl) benzoic acid (compound 2) and 2-(dibenzothiophene-2carbonyl)octadecyl benzoate (compound 4), 2-(dibenzothiophene-2-carbonyl)hexyl benzoate (compound 5) and 2-(dibenzo[b,d]thiophene-2-carbonyl)ethyl benzoate (compound 6) were designed as shown in Scheme 1 (Katagiri et al. 2012).

2.2.1.1 Preparation of 2-(dibenzothiophene-2-carbonyl) benzoic acid (compound 2) Aluminum chloride (3.13 g, i.e., $23.5 \mathrm{mmol}$ ) was added to a solution of phthalic anhydride $(0.87 \mathrm{~g}$, i.e., $5.88 \mathrm{mmol})$ in 1,2-dichloroethane $(20 \mathrm{~mL})$, at $-20{ }^{\circ} \mathrm{C}$ using a cooling water circulator and stirred for $1 \mathrm{~h}$. Then, a solution of dibenzothiophene (1.08 g, i.e., $5.88 \mathrm{mmol})$ and 1,2-dichloroethane $(20 \mathrm{~mL})$ was added dropwise. The resultant mixture was stirred for $24 \mathrm{~h}$ at
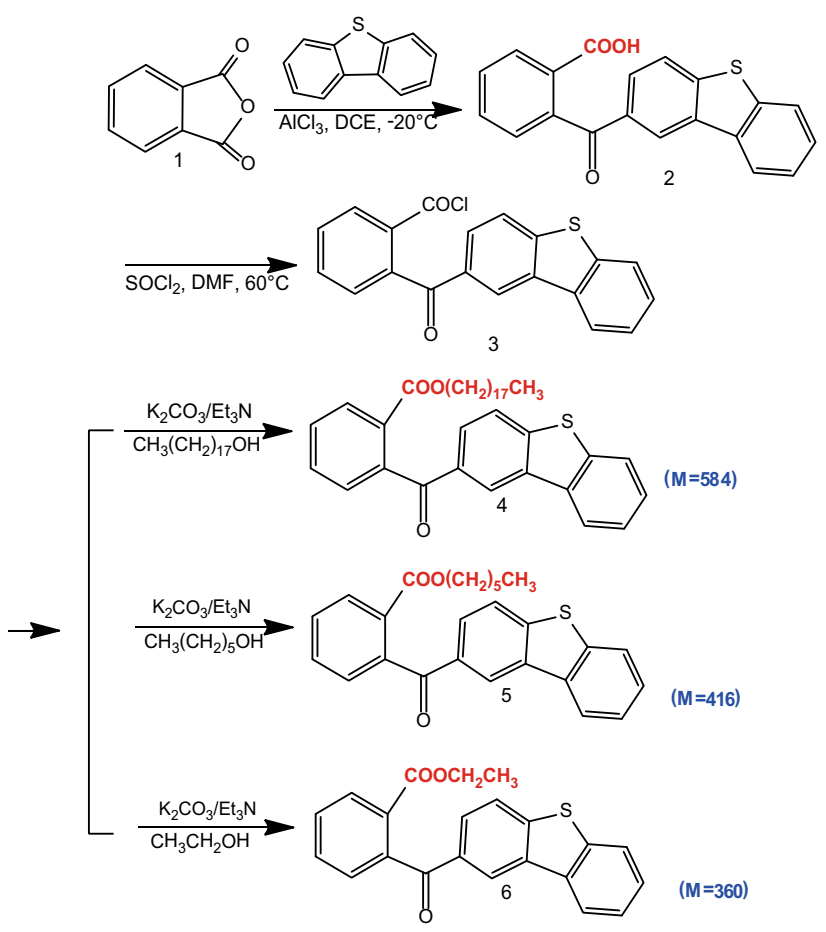

Scheme 1 Synthesis of 2-(dibenzothiophene-2-carbonyl)benzoic acid (compound 2) and octadecyl, hexyl, ethyl 2-(dibenzothiophene2-carbonyl)benzoate (compounds $4,5,6$, respectively) 
$-20{ }^{\circ} \mathrm{C}$ under nitrogen and then treated with $30 \mathrm{~mL} 10 \%$ aqueous hydrochloric acid and stirred for $10 \mathrm{~min}$. Then the mixture was extracted with $200 \mathrm{~mL}$ dichloromethane. The organic layer was washed with $200 \mathrm{~mL}$ water, and $100 \mathrm{~mL}$ saturated salt water, and then dried over anhydrous sodium sulfate. The solvent was removed under reduced pressure, and the residue was purified by column chromatography on silica gel (dichloromethane/methanol $=10 / 1$ ). Then the product was purified by recrystallization and dried in a vacuum oven to obtain compound $\mathbf{2}$ as a yellow powder with a yield of $40 \%(0.78 \mathrm{~g})$.

2.2.1.2 Preparation of 2-(dibenzothiophene-2-carbonyl) octadecyl benzoate (compound 4) First, thionyl chloride $(5.24 \mathrm{~mL})$ and DMF $(1 \mu \mathrm{L})$ were added to carboxylic acid (compound 2) $(0.19 \mathrm{~g}$, i.e., $0.57 \mathrm{mmol})$ at $0{ }^{\circ} \mathrm{C}$ under nitrogen and stirred at $60{ }^{\circ} \mathrm{C}$ for $3 \mathrm{~h}$, then the excess thionyl chloride was removed under high vacuum to obtain acyl chloride which was used without purification. Then, octadecanol powder $(0.15 \mathrm{~g}$, i.e., $0.57 \mathrm{mmol})$ and ethylenediamine $(81 \mu \mathrm{L})$ were added to the solution of acyl chloride $(0.019 \mathrm{M})$ in dichloromethane $(20 \mathrm{~mL})$, and stirred for $6 \mathrm{~h}$ at room temperature. After that, the solvent was removed under reduced pressure, and the residue was purified by column chromatography on silica gel (petroleum ether/acetone $=10 / 1$ ). The product was purified by recrystallization and then dried in a vacuum oven to give the carboxylic ester (compound 4) as a pale yellow powder with a yield of $66 \%(0.22 \mathrm{~g})$.

\subsubsection{Preparation of 2-(dibenzothiophene-2-carbonyl)hexyl} benzoate (compound 5) Hexyl alcohol (71.5 $\mu \mathrm{L}$, i.e., $0.57 \mathrm{mmol})$ and ethylenediamine $(81 \mu \mathrm{L})$ were added to a solution of acyl chloride $(0.019 \mathrm{~mol} / \mathrm{L})$ in dichloromethane $(20 \mathrm{~mL})$. The synthesis and post-processing method was similar to that for compound 4. The carboxylic ester (compound 5) was a pale yellow powder, and the yield was $72 \%(0.17 \mathrm{~g})$.

2.2.1.4 Preparation of 2-[dibenzo(b,d)thiophene-2-carbonyl]ethyl benzoate (compound 6) Alcohol (33 $\mu \mathrm{L}$, i.e., $0.57 \mathrm{mmol})$ and ethylenediamine $(81 \mu \mathrm{L})$ were added to a solution of acyl chloride $(0.019 \mathrm{~mol} / \mathrm{L})$ in dichloromethane $(20 \mathrm{~mL})$. The synthesis and post-processing method was similar to that for compound 4. The carboxylic ester (compound 6) $(0.15 \mathrm{~g}, 73 \%)$ was a pale yellow powder, and the yield was $73 \%(0.15 \mathrm{~g})$.

\subsubsection{Characterization of dibenzothiophene derivatives}

2.2.2.1 2-(Dibenzothiophene-2-carbonyl)benzoic acid (compound 2) M.p. $202{ }^{\circ} \mathrm{C} ;{ }^{1} \mathrm{H}$ NMR (600 MHz, $\left.\mathrm{CDCl}_{3}\right) \delta$ $8.51(\mathrm{~s}, 1 \mathrm{H}), 8.10(\mathrm{~d}, \mathrm{~J}=7.3 \mathrm{~Hz}, 1 \mathrm{H}), 8.05(\mathrm{~d}, \mathrm{~J}=7.9 \mathrm{~Hz}$, 1H), 7.86-7.81 (m, 1H), $7.78(\mathrm{~d}, \mathrm{~J}=8.4 \mathrm{~Hz}, 1 \mathrm{H}), 7.71$ $(\mathrm{dd}, \mathrm{J}=8.4,1.3 \mathrm{~Hz}, 1 \mathrm{H}), 7.66(\mathrm{td}, \mathrm{J}=7.6,0.8 \mathrm{~Hz}, 1 \mathrm{H})$, $7.55(\mathrm{td}, \mathrm{J}=7.8,1.0 \mathrm{~Hz}, 1 \mathrm{H}), 7.50-7.42(\mathrm{~m}, 2 \mathrm{H}), 7.40(\mathrm{~d}$, $\mathrm{J}=7.4 \mathrm{~Hz}, 1 \mathrm{H})$, (COOH signal not observed); MALDITOF MS calcd for $\mathrm{C}_{20} \mathrm{H}_{12} \mathrm{O}_{3} \mathrm{~S} \mathrm{~m} / \mathrm{z}=332.4$, found 354.9 $[\mathrm{M}+\mathrm{Na}]^{+}$. Anal. calc. for $\mathrm{C}_{20} \mathrm{H}_{12} \mathrm{O}_{3} \mathrm{~S}: \mathrm{C}$ 72.27, H 3.64, found C 71.96, H 3.63.

2.2.2.2 2-(Dibenzothiophene-2-carbonyl)octadecyl benzoate (compound 4) M.p. 85.2 ${ }^{\circ} \mathrm{C} ;{ }^{1} \mathrm{H} \mathrm{NMR}\left(\mathrm{CDCl}_{3}\right) \delta 8.35(\mathrm{~s}$, $1 \mathrm{H}), 8.22-8.13(\mathrm{~m}, 1 \mathrm{H}), 7.95(\mathrm{~d}, \mathrm{~J}=7.6 \mathrm{~Hz}, 1 \mathrm{H}), 7.86(\mathrm{t}$, $\mathrm{J}=8.6 \mathrm{~Hz}, 2 \mathrm{H}), 7.66(\mathrm{dd}, \mathrm{J}=15.7,8.1 \mathrm{~Hz}, 2 \mathrm{H}), 7.58(\mathrm{t}$, $\mathrm{J}=7.4 \mathrm{~Hz}, 1 \mathrm{H}), 7.53(\mathrm{~d}, \mathrm{~J}=7.6 \mathrm{~Hz}, 1 \mathrm{H}), 7.47$ (dd, $\mathrm{J}=5.8,3.2 \mathrm{~Hz}, 2 \mathrm{H}), 3.58(\mathrm{~d}, \mathrm{~J}=8.8 \mathrm{~Hz}, 1 \mathrm{H}), 3.39(\mathrm{~d}$, $\mathrm{J}=8.6 \mathrm{~Hz}, 1 \mathrm{H}), 1.74-1.60(\mathrm{~m}, 2 \mathrm{H}), 1.37(\mathrm{~s}, 2 \mathrm{H}), 1.24(\mathrm{~s}$, $28 \mathrm{H}), 0.88(\mathrm{t}, \mathrm{J}=6.6 \mathrm{~Hz}, 3 \mathrm{H})$. MALDI-TOF MS calcd for $\mathrm{C}_{38} \mathrm{H}_{48} \mathrm{O}_{3} \mathrm{~S} m / z=584.8$, found $607.4[\mathrm{M}+\mathrm{Na}]^{+}$. Anal. calc. for $\mathrm{C}_{38} \mathrm{H}_{48} \mathrm{O}_{3} \mathrm{~S}$ : C 78.05, $\mathrm{H} 8.27$, found $\mathrm{C} 78.11, \mathrm{H}$ 8.25 .

2.2.2.3 2-(Dibenzothiophene-2-carbonyl)hexyl benzoate (compound 5) M.p. 68.2 ${ }^{\circ} \mathrm{C} ;{ }^{1} \mathrm{H} \mathrm{NMR}\left(\mathrm{CDCl}_{3}\right) \delta 8.35(\mathrm{~s}$, $1 \mathrm{H}), 8.17(\mathrm{dd}, \mathrm{J}=5.7,3.3 \mathrm{~Hz}, 1 \mathrm{H}), 7.95(\mathrm{~d}, \mathrm{~J}=7.6 \mathrm{~Hz}$, $1 \mathrm{H}), 7.85(\mathrm{dd}, \mathrm{J}=6.3,3.3 \mathrm{~Hz}, 2 \mathrm{H}), 7.67(\mathrm{dd}, \mathrm{J}=15.6$, $8.0 \mathrm{~Hz}, 2 \mathrm{H}), 7.58(\mathrm{t}, \mathrm{J}=7.4 \mathrm{~Hz}, 1 \mathrm{H}), 7.53(\mathrm{~d}, \mathrm{~J}=7.6 \mathrm{~Hz}$, 1H), 7.47 (dt, J = 7.1, 3.6 Hz, 2H), $3.59(\mathrm{~d}, \mathrm{~J}=8.8 \mathrm{~Hz}$, $1 \mathrm{H}), \quad 3.40(\mathrm{~d}, \mathrm{~J}=8.8 \mathrm{~Hz}, 1 \mathrm{H}), 1.74-1.60(\mathrm{~m}, 2 \mathrm{H})$, 1.44-1.34 (m, 2H), 1.33-1.23 (m, 4H), $0.88(\mathrm{t}, \mathrm{J}=6.8 \mathrm{~Hz}$, 3H).MALDI-TOF MS calcd for $\mathrm{C}_{26} \mathrm{H}_{24} \mathrm{O}_{3} \mathrm{~S} \mathrm{~m} / \mathrm{z}=416.5$, found 439.1[M+Na] ${ }^{+}$. Anal. calc. for $\mathrm{C}_{26} \mathrm{H}_{24} \mathrm{O}_{3} \mathrm{~S}$ : C 74.97, H 5.81, found C 74.86, H 5.79.

2.2.2.4 2-(Dibenzo[b,d]thiophene-2-carbonyl)ethyl benzoate (compound 6) M.p. $51.1{ }^{\circ} \mathrm{C} ;{ }^{1} \mathrm{H} \mathrm{NMR}\left(\mathrm{CDCl}_{3}\right) \delta$ $8.37(\mathrm{~s}, 1 \mathrm{H}), 8.19(\mathrm{dd}, \mathrm{J}=6.0,3.1 \mathrm{~Hz}, 1 \mathrm{H}), 7.95(\mathrm{~d}$, $\mathrm{J}=7.6 \mathrm{~Hz}, 1 \mathrm{H}), 7.91-7.81(\mathrm{~m}, 2 \mathrm{H}), 7.71-7.63(\mathrm{~m}, 2 \mathrm{H})$, $7.62-7.52(\mathrm{~m}, 2 \mathrm{H}), 7.48(\mathrm{dd}, \mathrm{J}=5.9,3.1 \mathrm{~Hz}, 2 \mathrm{H})$, 3.81-3.58 (m, 1H), 3.58-3.41 (m, 1H), 1.29 (dd, J = 17.8, $10.8 \mathrm{~Hz}, 3 \mathrm{H})$; MALDI-TOF MS calcd for $\mathrm{C}_{22} \mathrm{H}_{16} \mathrm{O}_{3} \mathrm{~S} \mathrm{~m} /$ $z=360.4$, found $361[\mathrm{M}+\mathrm{H}]^{+}$and $383[\mathrm{M}+\mathrm{Na}]^{+}$. Anal. calc. for $\mathrm{C}_{22} \mathrm{H}_{16} \mathrm{O}_{3} \mathrm{~S}$ : C 73.31, $\mathrm{H} 4.48$, found $\mathrm{C} 73.01, \mathrm{H}$ 4.47.

\section{Results and discussion}

\subsection{Molecular synthesis and characterization}

Satisfactory elemental analysis results were obtained for these newly synthesized compounds after column chromatography purification and recrystallization. The MALDI-TOF mass spectra of the compounds clearly 
showed an intense signal for $[\mathrm{M}+\mathrm{Na}]^{+}$. These dibenzothiophene derivatives were also characterized by spectroscopic methods, including ${ }^{1} \mathrm{H}$ NMR, FT-IR, and UV-Vis spectra. The proposed structures of the compounds were confirmed by these analysis results.

Compound $\mathbf{2}$ was highly soluble in most organic solvents, including dichloromethane $\left(\mathrm{CH}_{2} \mathrm{Cl}_{2}\right)$, acetone $\left(\mathrm{CH}_{3} \mathrm{COCH}_{3}\right)$, tetrahydrofuran (THF), N,N-dimethyl formamide (DMF), dimethyl sulfoxide (DMSO), chloroform $\left(\mathrm{CHCl}_{3}\right)$, and acetonitrile $\left(\mathrm{CH}_{3} \mathrm{CN}\right)$. However, except for dichloromethane and acetonitrile, the UV-Vis absorption of the organic solvents affected the absorption band of compound 2. Therefore, dichloromethane and acetonitrile were the best solvents for study of the self-aggregation behavior of compound 2 .

\subsection{Aggregation studies}

The self-aggregation depends on substituents of the compound, concentration of the solution and nature of the solvent (Bayrak et al. 2011; Öztürk et al. 2012). In this work, the self-aggregation of compound $\mathbf{2}$ and compounds 4-6 was investigated by $\mathrm{UV}-\mathrm{V}$ is spectroscopy in $\mathrm{CH}_{2} \mathrm{Cl}_{2}$ and $\mathrm{CH}_{3} \mathrm{CN}$, respectively.

As shown in Fig. 1, with the concentration of compound 2 in $\mathrm{CH}_{3} \mathrm{CN}$ being increased from $10^{-6}$ to $5 \times 10^{-5} \mathrm{M}$, the absorption intensity increased and no new bands formed. The inset of Fig. 1 shows the change of absorption intensity of compound 2 at $241 \mathrm{~nm}$ with its concentration in $\mathrm{CH}_{3} \mathrm{CN}$. It could be seen that the Beer-Lambert law was obeyed for compound $\mathbf{2}$ in the concentration range from $10^{-6}$ to $5 \times 10^{-5} \mathrm{M}$. These results indicated that

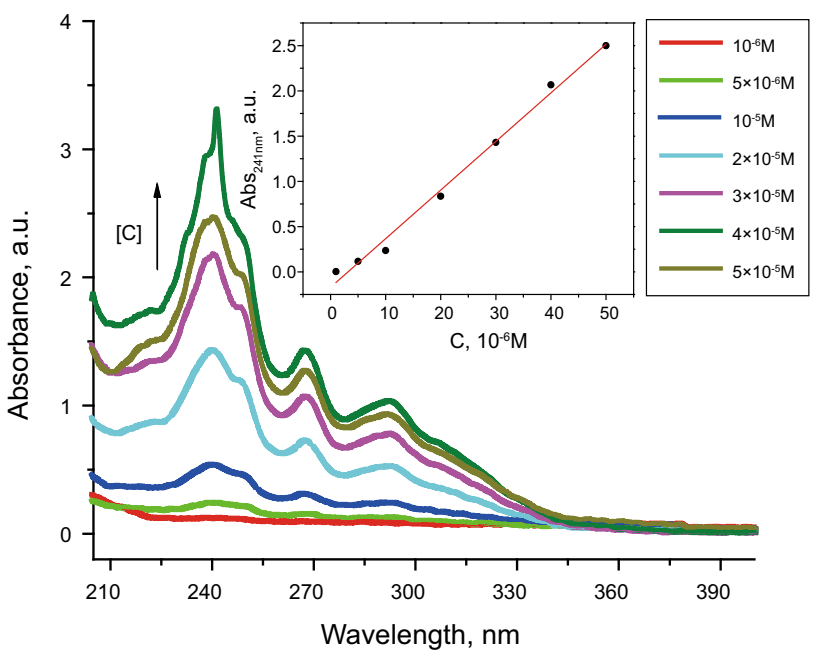

Fig. 1 UV-Vis spectra of compound 2 with different concentrations in $\mathrm{CH}_{3} \mathrm{CN}$. Inset shows the absorbance change of compound 2 with its concentration (C) in $\mathrm{CH}_{3} \mathrm{CN}$ compound 2 was stable and not aggregated in $\mathrm{CH}_{3} \mathrm{CN}$ in the range of $10^{-6} \sim 5 \times 10^{-5} \mathrm{M}$ (Bayrak et al. 2011; Öztürk et al. 2012). However, in the concentration range of $10^{-8} \sim 8 \times 10^{-6} \mathrm{M}$, the absorption intensity of compound 2 in $\mathrm{CH}_{2} \mathrm{Cl}_{2}$ was dependent on concentration, as shown in Fig. 2. The inset of Fig. 2 shows the change of absorption intensity at $241.5 \mathrm{~nm}$ with concentration of compound 2. As shown in the inset, with concentration increasing from $10^{-8}$ to $2 \times 10^{-7} \mathrm{M}$, the absorption intensity at $241.5 \mathrm{~nm}$ increased, but with further increasing concentration from $2 \times 10^{-7}$ to $5 \times 10^{-7} \mathrm{M}$, the absorption intensity decreased significantly, and then the absorption intensity increased again with the concentration increasing from $5 \times 10^{-7}$ to $8 \times 10^{-6} \mathrm{M}$. It suggests the formation of aggregates of compound 2 in the $\mathrm{CH}_{2} \mathrm{Cl}_{2}$ solutions $\left(2 \times 10^{-7}\right.$ to $\left.5 \times 10^{-7} \mathrm{M}\right)$. The self-assembly behavior of compound 2 in $\mathrm{CH}_{2} \mathrm{Cl}_{2}$ resulted in a decrease of the absorption intensity in the range of $2 \times 10^{-7} \sim 5 \times 10^{-7} \mathrm{M}$ (Bayrak et al. 2011; Öztürk et al. 2012). When the concentration exceeded $10^{-6} \mathrm{M}$, it was reasonable to assume that there was equilibrium with higher aggregates. These results demonstrated that the compound $\mathbf{2}$ could be stabilized by polar solvents and was more stable in $\mathrm{CH}_{3} \mathrm{CN}$ than $\mathrm{CH}_{2} \mathrm{Cl}_{2}$.

To investigate the role that hydrogen bonding and $\pi-\pi$ stacking play in the aggregation process of compound $\mathbf{2}$, the carboxylic acid group of compound 2 was protected by octadecyl, hexyl, and ethyl ester to obtain compounds $\mathbf{4 , 5}$, 6, respectively. Then the UV-Vis spectra of compounds 4 6 were obtained and studied (Fig. 3). Taking the UV-Vis spectrum of compound 4 as an example, it can be seen from Fig. 3a and the inset (the change of absorption

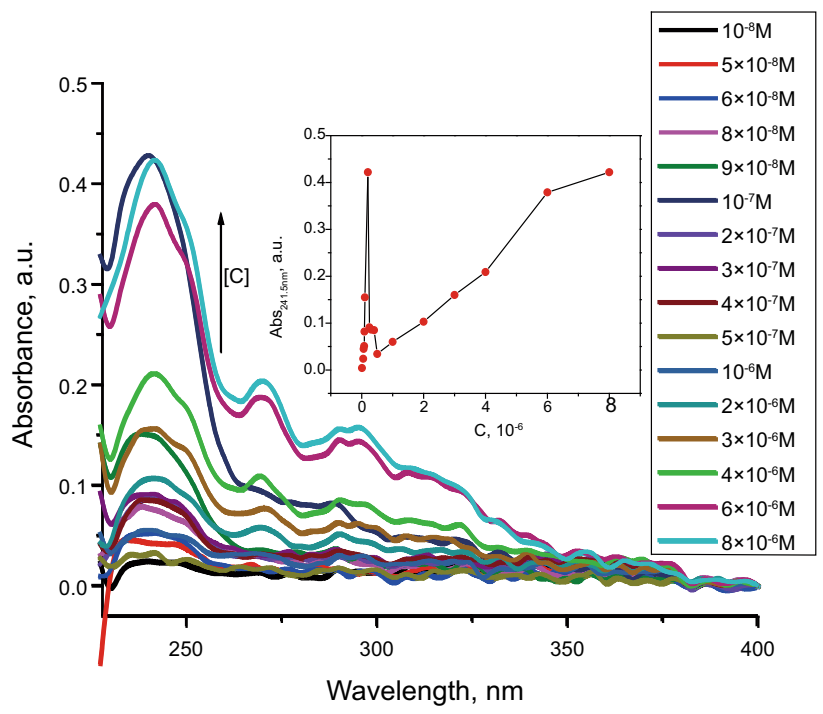

Fig. 2 UV-Vis spectra of compound 2 with different concentrations in $\mathrm{CH}_{2} \mathrm{Cl}_{2}$. Inset shows the absorbance change of compound 2 with its concentration (C) in $\mathrm{CH}_{2} \mathrm{Cl}_{2}$ 

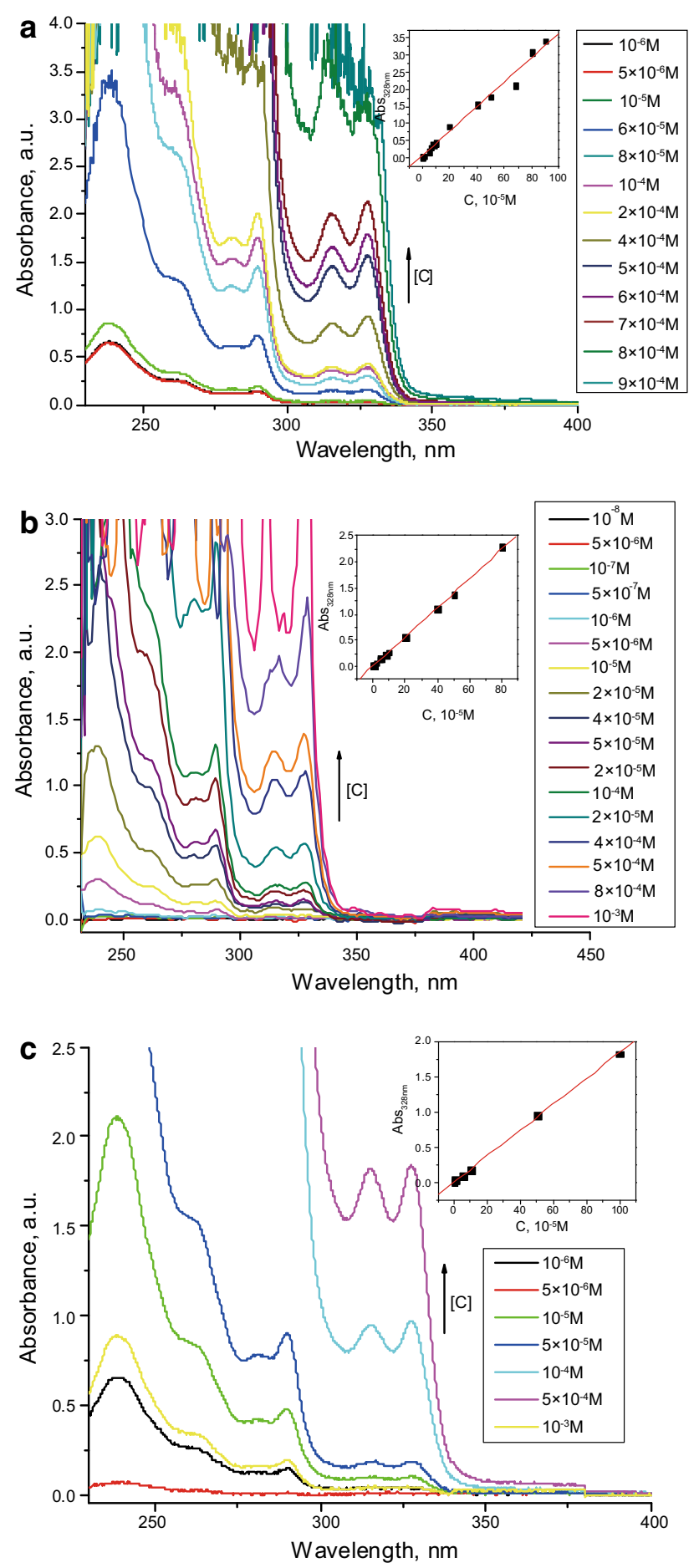

Fig. 3 UV-vis spectra of carboxylic esters with different concentrations in $\mathrm{CH}_{2} \mathrm{Cl}_{2}$. a compound $4 ; \mathbf{b}$ compound 5 ; c compound 6 . Insets show the absorbance change of compounds $4,5,6$, respectively, with their concentration $(\mathrm{C})$ in $\mathrm{CH}_{2} \mathrm{Cl}_{2}$ intensity at $328 \mathrm{~nm}$ with the concentration of compound 4), with an increase of concentration, the absorption intensity increased and no new bands are formed. The Beer-Lambert law was obeyed for compound 4 in $\mathrm{CH}_{2} \mathrm{Cl}_{2}$ in the concentration range of $10^{-6}-9 \times 10^{-4} \mathrm{M}$. A similar study was made for compounds 5 and $\mathbf{6}$ (Fig. 3b, c). The $\mathrm{CH}_{2} \mathrm{Cl}_{2}$ solution of compounds $\mathbf{5}$ and $\mathbf{6}$ obeyed the Beer-Lambert law in the concentration range of $10^{-8}-10^{-3} \mathrm{M}$. These results indicated that there were no self-assembled aggregates formed in the solution of these carboxylic esters (compounds $4,5,6$ ) in the investigated concentration range of $10^{-8}-10^{-3} \mathrm{M}$, and $\pi-\pi$ stacking did not participate in the formation of aggregates of compound 2 . The results proved the dominant role of hydrogen bonding in the selfaggregation of compound $\boldsymbol{2}$.

Solid state FT-IR can also be useful in showing the ionic nature of hydrogen in the aggregation of compound 2 (Lee and Wang 2010; Das and Baruah 2011). To probe hydrogen bonds among the carboxylic acid groups, the FT-IR spectra of compound 2 and compounds 4-6 were compared. As shown in Fig. 4, the FT-IR spectrum of compound 2 showed a hydroxyl absorption in the region of 3400-3500 $\mathrm{cm}^{-1}$, and the hydroxyl absorption disappeared in the FT-IR spectra of compounds 4-6 after the formation of carboxylic esters. The absorption of hydroxyl of compound $\mathbf{2}$ was assigned to the absorption region of hydrogen bonding, including the absorption of individual hydroxyl,

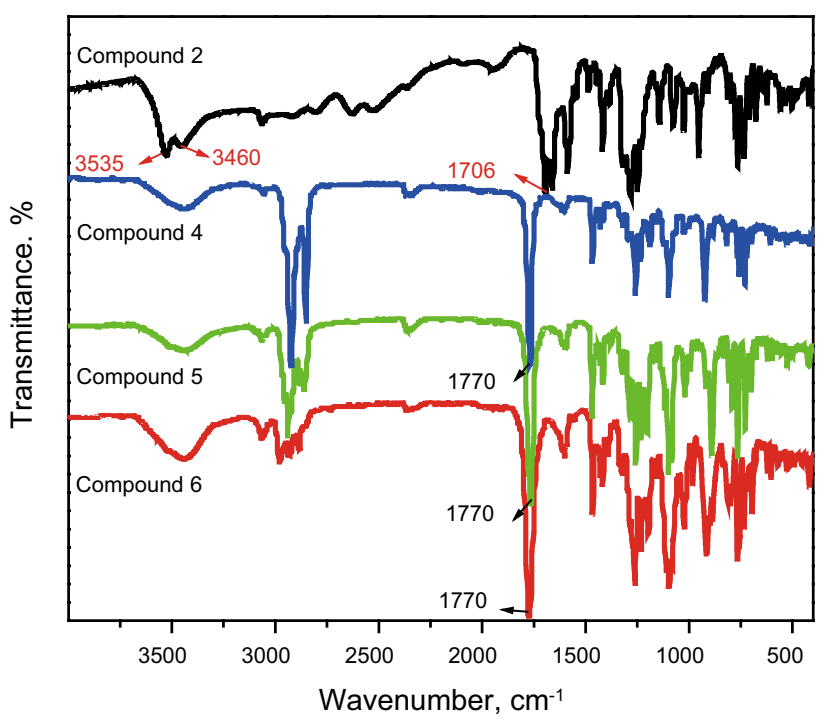

Fig. 4 FT-IR spectra of compounds 2-6 


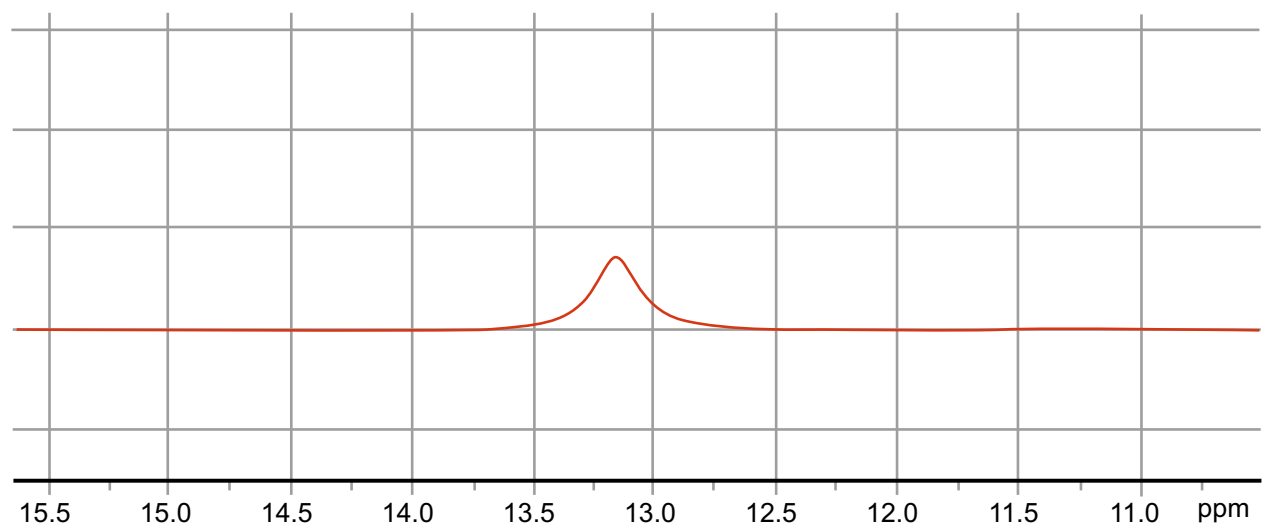

Fig. $5{ }^{1} \mathrm{H}$ NMR spectra of a nominally $0.020 \mathrm{M}$ solution of compound 2 in DMSO-d $\mathrm{d}_{6}$ at $600 \mathrm{MHz}$ and the horizontal axis is the chemical shift (ppm)

intramolecular hydrogen bonding and hydrogen bonding between molecules (Liu et al. 2010; Fitié et al. 2011). When the carboxylic acid group was protected by octadecyl, hexyl, and ethyl esters, the carbonyl stretching frequency shifted from $\approx 1706$ to $\approx 1770 \mathrm{~cm}^{-1}$, which suggested the existence of hydrogen bonds (Molla et al. 2014; Fitié et al. 2011).

The ${ }^{1} \mathrm{H}$ NMR signals at low fields (12-15 ppm) are good reporters of the environment around hydrogen-bonded protons (Suárez et al. 1998; Chin et al. 1997). As shown in Fig. 5, the ${ }^{1} \mathrm{H}$ NMR spectrum of compound 2 in DMSO-d showed one peak in this region (13.3 ppm). The peak is the signal for hydrogen-bonded protons.

Based on UV-Vis, FT-IR spectroscopy and ${ }^{1} \mathrm{H}$ NMR of compound $\mathbf{2}$ mentioned above, it can be concluded that the H-bonds between different compound $\mathbf{2}$ molecules could result in the self-assembly of aggregates. A possible growing mode of the compound $\mathbf{2}$ assembly is shown in Scheme 2. To gain more insight into the self-aggregation of compound $\mathbf{2}$, solutions of compound 2 with concentrations of $10^{-8}, 5 \times 10^{-7}$, and $10^{-5} \mathrm{M}$ were investigated using AFM. The sample was prepared by dripping a drop of the solutions of compound $\mathbf{2}$ on a mica sheet, and then the solvent was quickly evaporated under vacuum. The AFM image of Fig. 6a shows no aggregates formed in the $10^{-8} \mathrm{M}$ solution of compound $\mathbf{2}$, it was reasonable to assume that the concentration of solution was not high enough to form the aggregates. Nanoparticles of aggregates

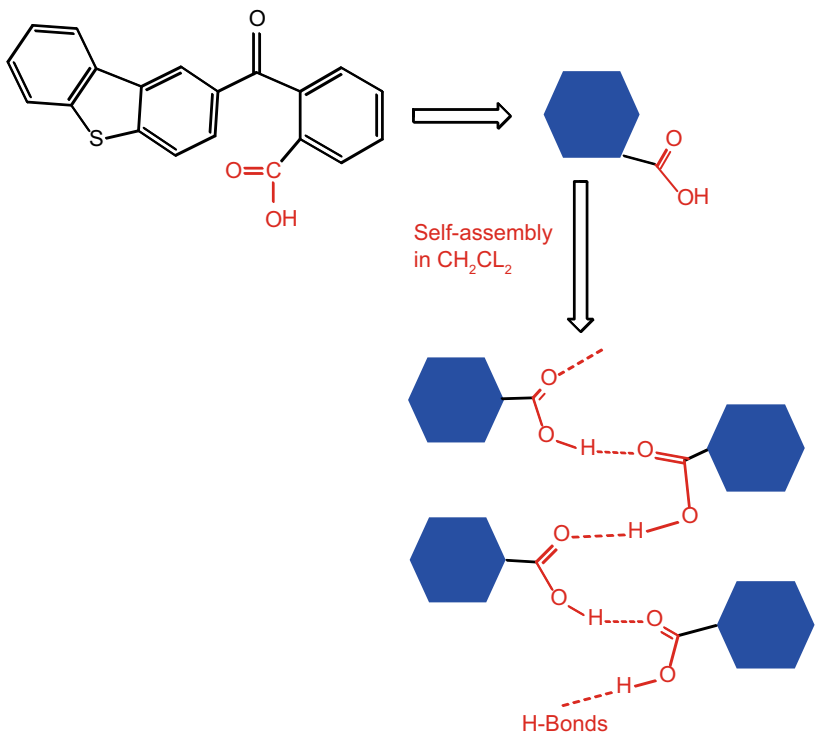

Scheme 2 Schematic presentation for the self-assembly of 2-(dibenzothiophene-2-carbonyl) benzoic acid in $\mathrm{CH}_{2} \mathrm{Cl}_{2}$ solution via H-bonds

were observed in the solution of $10^{-5}$ and $5 \times 10^{-7} \mathrm{M}$ (Fig. 6b, c), and the heights of the particles in the AFM image are about $2 \mathrm{~nm}$ (Fig. 6d, e), this phenomenon is in agreement with the result of an equilibrium with higher aggregates when the concentration of compound $\mathbf{2}$ solution exceeded $10^{-6} \mathrm{M}$. 

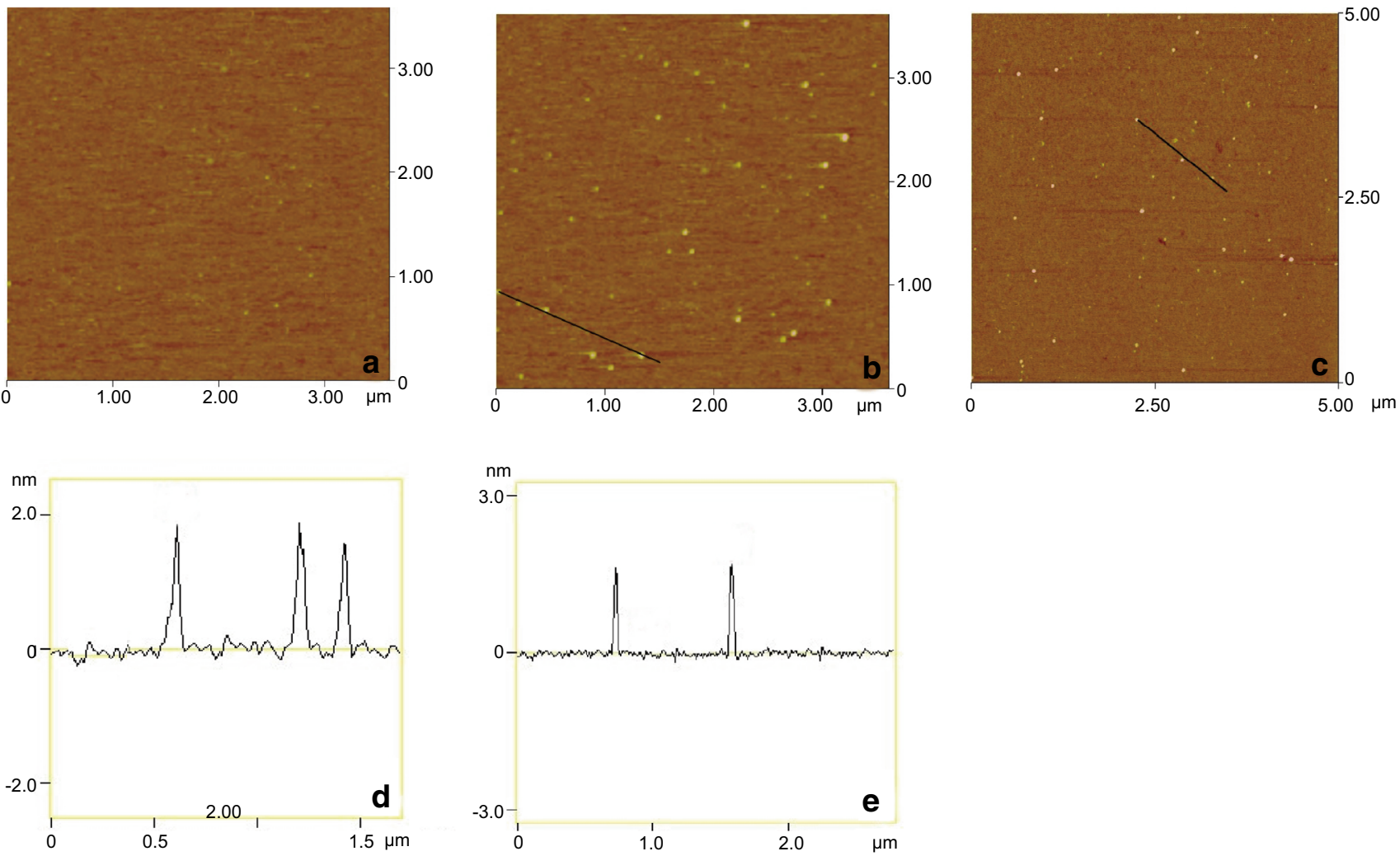

Fig. 6 The AFM representations of compound 2 solution: a $10^{-8} \mathrm{M} ; \mathbf{b} 5 \times 10^{-7} \mathrm{M} ; \mathbf{c} 10^{-5} \mathrm{M}$; and $\mathbf{d}$, e the cross-sectional views of the black lines in $\mathbf{b}$ and $\mathbf{c}$, respectively. The horizontal axis of images is the scale $(\mu \mathrm{m})$

\section{Conclusions}

The dibenzothiophene derivatives of compound $\mathbf{2}$ and compounds 4-6 were synthesized successfully and the selfassociation behavior of these compounds in $\mathrm{CH}_{2} \mathrm{Cl}_{2}$ and $\mathrm{CH}_{3} \mathrm{CN}$ were investigated. Compound 2 showed a strong association tendency in $\mathrm{CH}_{2} \mathrm{Cl}_{2}$ but no aggregates could be detected in the solution of compounds 4-6. UV-Vis and FT-IR spectra suggested that hydrogen bonding between the different molecules was the main driving force for the aggregation of compound $\mathbf{2}$. In the AFM photos, there were some nano-aggregates formed in the $10^{-5}$ and $5 \times 10^{-7} \mathrm{M}$ solutions of compound 2. These results supported the notion that hydrogen bonding played a key role in the aggregation of compound $\mathbf{2}$, which could simulate the hydrogen bonding interaction in the aggregation behavior of asphaltenes.

Acknowledgments The authors would like to thank the National Natural Science Foundation of China (No. 21376265) for financial support and the Fundamental Research Funds for the Central Universities (No. 14CX02008A).

Open Access This article is distributed under the terms of the Creative Commons Attribution 4.0 International License (http://creativecommons.org/licenses/by/4.0/), which permits unrestricted use, distribution, and reproduction in any medium, provided you give appropriate credit to the original author(s) and the source, provide a link to the Creative Commons license, and indicate if changes were made.

\section{References}

Akbarzadeh K, Bressler DC, Gray MR. Association behavior of pyrene compounds as models for asphaltenes. Energy Fuels. 2005;19(4):1268-71.

Bayrak R, Akçay HT, Durmuşet M, et al. Synthesis, photophysical and photochemical properties of highly soluble phthalocyanines substituted with four 3,5-dimethylpyrazole-1-methoxy groups. J Organomet Chem. 2011;696(23):3807-15.

Chin DN, Simanek EE, Li X, et al. Computations and ${ }^{1} \mathrm{H} n m r$ spectroscopy of the imide region can distinguish isomers of hydrogen-bonded aggregates. J Org Chem. 1997;62:1891-5.

Clair S, Pons S, Seitsonen A, et al. STM study of terephthalic acid self-assembly on $\mathrm{Au}(111)$ : hydrogen-bonded sheets on an inhomogeneous substrate. J Phy. Chem B. 2004;108(38): 14585-90.

Das B, Baruah JB. Assemblies of cytosine within H-bonded network of adipic acid and citric acid. J Mol Struct. 2011;1001(1):134-8.

Fitié CFC, Mendes E, Hempenius MA, et al. Self-assembled superlattices of polyamines in a columnar liquid crystal. Macromolecules. 2011;44(4):757-66.

Fuhr JD, Carrera N, Murillo-Quirós N, et al. Interplay between hydrogen bonding and molecule-substrate interactions in the 
case of terephthalic acid molecules on $\mathrm{Cu}(001)$ surfaces. J Phys Chem C. 2013;117(3):1287-96.

Gray MR, Tykwinski R, Tan XL, et al. Supramolecular assembly model for aggregation of petroleum asphaltenes. Energy Fuels. 2011;25(7):3125-34.

Grabowski SJ. Hydrogen bonds assisted by $\pi$-electron delocalizationthe influence of external intermolecular interactions on dimer of formic acid. J Phys Org Chem. 2008;21(7-8):694-702.

Groenzin H, Mullins OC. Molecular size and structure of asphaltenes from various sources. Energy Fuels. 2000;14(3):677-84.

Heininger C, Kampschulte L, Heckl W, et al. Distinct differences in self-assembly of aromatic linear dicarboxylic acids. Langmuir. 2009;25(2):968-72.

Katagiri H, Yamamoto K, Tairabune H, et al. Synthesis and properties of naphthobisbenzo[b]thiophenes: structural curvature of higher acene frameworks for solubility enhancement and high-order orientation in crystalline states. Tetrahedron Lett. 2012;53(14): 1786-9.

Lackinger M, Heckl W. Carboxylic acids: versatile building blocks and mediators for two-dimensional supramolecular self-assembly. Langmuir. 2009;25(19):11307-21.

Lee T, Wang PY. Screening, manufacturing, photoluminescence, and molecular recognition of co-crystals: cytosine with dicarboxylic acids. Cryst Growth Des. 2010;10:1419-34.

Liu D, Kong X, Li MY, et al. Study on the aggregation of residuederived asphaltene molecules. Energy Fuels. 2010;24(6):3624-7.

Molla MR, Roy L, Kamm V, et al. Self-assembly of carboxylic acid appended naphthalene diimide derivatives with tunable luminescent color and electrical conductivity. Chem Eur J. 2014;20(3):760-71.

Murgich J, Rodríguez MJ, Aray Y. Molecular recognition and molecular mechanics of micelles of some model asphaltenes and resins. Energy Fuels. 1996;10(1):68-76.

Murgich J. Intermolecular forces in aggregates of asphaltenes and resins. Pet Sci Technol. 2002;20(9-10):983-97.

Murgich J, Abanero JA, Strausz OP. Molecular recognition in aggregates formed by asphaltene and resin molecules from the Athabasca oil sand. Energy Fuels. 1999;13(2):278-86.
Nordgård EL, Sjöblom J. Model compounds for asphaltenes and $\mathrm{C}_{80}$ isoprenoid tetraacids. Part I: synthesis and interfacial activities. J Dispers Sci Technol. 2008;29(8):1114-22.

Nordgård EL, Sørland G, Sjöblom J. Behavior of asphaltene model compounds at W/O interfaces. Langmuir. 2010;26(4):2352-60.

Öztürk C, Erdoğmuş A, Durmuş M, et al. Highly soluble 3,4(dimethoxyphenylthio) substituted phthalocyanines: synthesis, photophysical and photochemical studies. Spectrochim. Acta A. 2012;86:423-43.

Rakotondradany F, Fenniri H, Gray MR, et al. Hexabenzocoronene model compounds for asphaltene fractions: synthesis \& characterization. Energy Fuels. 2006;20(6):2439-47.

Rogel E. Simulation of interactions in asphaltene aggregates. Energy Fuels. 2000;14(3):566-74.

Sheremata JM, Gray MR, Dettman HD, et al. Quantitative molecular representation and sequential optimization of Athabasca asphaltenes. Energy Fuels. 2004;18(5):1377-84.

Sheu EY. Petroleum asphaltene properties, characterization, and issues. Energy Fuels. 2002;16(1):74-82.

Strausz OP, Lown EM. The chemistry of Alberta oil sands, bitumens and heavy oils. Calgary: Alberta Energy Research Institute (AERI); 2003.

Suárez M, Lehn JM, Zimmerman SC, et al. Supramolecular liquid crystals. self-assembly of a trimeric supramolecular disk and its self-organization into a columnar discotic mesophase. J Am Chem Soc. 1998;120(37):9526-32.

Takanohashi T, Sato S, Tanaka R. Molecular dynamics simulation of structural relaxation of asphaltene aggregates. Pet Sci Technol. 2003;21(3-4):491-505.

Tan XL, Fenniri H, Gray MR. Water enhances the aggregation of model asphaltenes in solution via hydrogen bonding. Energy Fuels. 2009;23(7):3687-93.

Ye Y, Sun W, Wang YF, et al. A unified model: self-assembly of trimesic acid on gold. J Phys Chem C. 2007;111(28):10138-41.

Zhao S, Kotlyar LS, Woods JR. Molecular transformation of Athabasca bitumen end-cuts during coking and hydrocracking. Fuel. 2001;80(8):1155-63. 